\title{
ALIH KODE DALAM BEBERAPA VIDEO PODCAST DEDDY CORBUZIER
}

\author{
Alif Maulana Syahrul Zidan*1, Syamsul Anwar ${ }^{2}$, Vita Ika Sari ${ }^{3}$ \\ ${ }^{* 1,2,3}$ Program Studi Pendidikan Bahasa dan Sastra Indonesia, Fakultas Keguruan dan Ilmu Pendidikan, \\ Universitas Pancasakti Tegal, Indonesia \\ e-mail: *1aliefmaul98@gmail.com, ${ }^{2}$ syamsulanwar590@gmail.com, ${ }^{3}$ vitaidea859799@gmail.com
}

\begin{abstract}
ABSTRAK
Tujuan kajian ini menggambarkan jenis dari berbagai faktor penyebab terjadinya peralihan kode pada podcast Deddy Corbuzier dan mendeskripsikan. Alasan memilih topik penelitian ini adalah karena di dalam topik ini terdapat sebuah permasalahan bahasa, dan masih jarang yang meneliti penelitian jenis alih kode yang subjeknya mengambil dari video podcast, Penelitian ini merupakan penelitian kualitatif. Alih kode yang diperoleh dalam podcast Deddy Corbuzier ditemukan 25 data. Pendekatan yang digunakan dalam penelitian ini adalah pendekatan deskriptif kualitatif. Metode yang digunakan dalam penelitian ini menggunakan metode deskriptif. Sumber data dalam penelitian ini adalah percakapan yang ada pada podcast Deddy Corbuzier. Teknik pengumpulan data dalam penelitian ini disebut teknik simak bebas cakap. Teknik analisis data dalam penelitian ini adalah teknik analisis deskriptif. Teknik penyajian hasil analisis dalam penelitian ini adalah teknik informal. Berdasarkan hasil penelitian dan analisis data tentang alih kode dalam podcast Deddy Corbuzier. Implikasinya terhadap pembelajaran bahasa Indonesia di SMA adalah terdapat banyaknya variasi bahasa yang digunakan dalam video podcast dan terdapat banyak pula faktor penyebab terjadinya peralihan kode dalam pembicaraan podcast tersebut, selain itu juga terdapat informasi yang bermanfaat juga untuk dipelajari oleh siswa.
\end{abstract}

Kata Kunci : Alih kode, podcast, implikasi.

\begin{abstract}
The purpose of this study is to describe the types and factors that cause code switching on Deddy Corbuzier's podcast. The reason for choosing this research topic is because in this topic there is a language problem, and this type of research is still rare. code switching whose subject is taken from a video podcast. This research is a qualitative research. The code switching obtained in Deddy Corbuzier's podcast found 25 data. The approach used in this study is a qualitative descriptive approach. The method used in this research is descriptive method. The source of the data in this research is the conversation that is on the Deddy Corbuzier podcast. Data collection technique in this is called the free-talk listening technique. Data analysis technique in this research is descriptive analysis technique. The technique of presenting the results of the analysis in this study is an informal technique. Based on the results of research and data analysis on Deddy Corbuzier's code switching and games used in high school, there are many variations of the language used in video podcasts and many factors that cause the code to appear in the podcast, besides that there is also useful information for students to learn.
\end{abstract}

Keywords: Code switching, podcasts, implications.

\section{PENDAHULUAN}

Manusia saling berhubungan memakai bahasa. Bahasa digunakan pada cakupan masyarakat, pada sebuah tindakan kemasyarakatan, ialah untuk menjalin kedekatan bersama masyarakat. Bahasa amat berguna untuk kegiatan hubungan kemasyarakatan. Bahasa melambangkan asal bunyi yang keluar pada mulut manusia yang mempunyai makna dan mampu dimengerti orang lain atas maksud membagikan jabaran masyarakat saat ini daripada beberapa besar manusia dinamakan dwibahasawan. Jika seseorang dinamakan dwibahasawan ketika menguasai dua bahasa. Hal ini seseorang memiliki dua bahasa yang dikuasainya yaitu bahasa pertama dan bahasa kedua atau lebih [1]. Bahasa merupakan alat komunikasi yang berupa sistem clef, yaitu alat bantu bahasa manusia. Komunikasi diartikan dalam bentuk sistem yang dimiliki manusia dalam aktivitas sehari-hari. Meskipun sebagian besar kegiatan komunikasi tertulis menggunakan bahasa nasional, bahasa daerah memegang peranan yang sangat penting dalam 
Jurnal SEMANTIKA, Volume 3, No. 02, Februari 2022, pp. 121-127

komunikasi antarmasyarakat dalam komunikasi antaretnis. Bahasa daerah sering digunakan untuk menyampaikan ilmu pengetahuan di lembaga-lembaga yang berkaitan dengan kehidupan masyarakat, seperti agama dan budaya. Orang yang menggunakan lebih dari satu bahasa ketika berbicara disebut komunitas bilingual dan multilingual. Bahasa, di sisi lain, termasuk tidak hanya dalam percakapan pribadi, tetapi juga dalam perkembangan teknologi dan percakapan melalui media komunikasi yang lebih baru dan lebih maju [2]. Bahasa adalah alat komunikasi yang merupakan sistem lambang bunyi sebagai alat bahasa manusia. Komunikasi adalah makna sistem dalam kehidupan manusia sehari-hari. Bahasa ialah alat komunikasi yang merupakan sistem lambang bunyi sebagai alat ujar manusia. Komunikasi mempunyai pengertian yaitu sistem yang dimiliki oleh manusia pada kegiatan sehari-hari. Aktivitas manusia memerlukan proses dan capaian komunikasi yang luas, sehingga amatlah berpotensi para pembicara menggunakan bahasa melebihi dari satu. Jikalau dua bahasa maupun lebih dipakai secara bergiliran oleh seorang pembicara dapat diungkapkan bahwa orang itu termasuk keadaan beralih kode [3]. Pemilihan kode terdapat pada situasi yang dipakai dalam hubungan. Keadaan yang dimaksud melibatkan dua perihal, yaitu latar sosial dan latar kultural.Latar sosial berhubungan mengenai prestise maupun nilai lebih pada ragam bahasa saat pakai dalam peristiwa tuturan oleh pembicara, dan latar kultural berhubungan atas unggah-ungguh dan pemahaman pembicara mengenai budaya atas suatu masyarakat tutur [4].

Dalam berkomunikasi penutur memakai bahasa tergantung pada situasi juga mitra tuturnya, kemudian pada suatu kejadian tertentu pembicara dapat saja memakai dua bahasa atau lebih. Hal tersebut dapat terjadi dikarenakan masyarakat Indonesia itu sendiri merupakan masyarakat yang memakai lebih dari satu bahasa atau lebih, yaitu ketika masyarakat memakai kedwibahasaan saat mereka berkomunikasi dengan satu sama lainnya. Dalam hal ini, tidak dapat dihindari bahwa orang dalam percakapan sehari-hari akan selalu memiliki pilihan untuk mengubah variasi bahasa, menggunakan satu kode bahasa untuk yang lain, atau mencampur kode bahasa dengan setiap interaksi. Perubahan kode internal adalah perubahan kode pada bahasa daerah yang menggunakan bahasa nasional, pada logat bahasa daerah, maupun pada beberapa jenis dialek. Perubahan kode keluar atau eksternal ialah perubahan kode yang dilakukan antara bahasa yang digunakan seharihari atau asal ke dalam bahasa luar atau asing. Penggunaan satu bahasa atau lebih untuk alih kode dapat dikenali apabila masing-masing bahasa mendukung ciri-cirinya sendiri-sendiri tergantung konteksnya dan ciri-ciri masing-masing bahasa disesuaikan dengan konteks yang terkait dengan perubahan kode tersebut.Dalam hal ini, dalam masyarakat bahasa sehari-hari, selalu ada peluang untuk mengubah variasi bahasa, menggunakan satu kode bahasa untuk menggunakan yang lain, dan mencampur kode bahasa dalam semua interaksi. Alih kode internal adalah alih kode yang terjadi antar bahasa daerah yang menggunakan bahasa nasional, antar logat bahasa daerah, atau antara beberapa jenis dan gaya dialek. Perubahan kode eksternal adalah perubahan kode yang dilakukan antara bahasa asli dengan bahasa asing. Penggunaan satu bahasa atau lebih untuk alih kode dapat dikenali apabila masing-masing bahasa mendukung ciri-cirinya masing-masing tergantung konteksnya dan ciri-ciri masing-masing bahasa disesuaikan dengan konteks yang terkait dengan perubahan kode tersebut. [5].

Pergantian alih kode hanya akan terjadi pada seseorang yang bisa atau menguasai lebih dari dua bahasa dan bukan terjadi antar bahasa. Dari pendapat itu, jelas untuk kita peralihan atas satu bahasa ke bahasa yang lainnya diujarkan seeorang akan bersamaan atas kedatangan pihak ketiga, peralihan atas variasi santai ke variasi resmi, bersamaan dengan beralihnya situasi santai ke situasi formal, proses peralihan diujarkan dengan sadar, penutur tidak menguasai kode yang dipakai atau sedang mempelajari kalimat serta kode yang terujar atas kode awalnya, dan yang lainnya. Seorang pembicara kadang kala beralih kode untuk memperoleh manfaat. Di pemerintahan tidak sedikit yang berujar dengan bahasa daerah untuk merasakan kesamaan satu daerah yang sama tuturannya, dan untuk meminta dukungan dari lawan bicaranya. Lawan tutur dapat menyebabkan alih kode untuk menyamai keahlian berbahasa si lawan bicaranya. Kedatangan pihak ketiga yang bukan berasal dari bahasa yang sama dengan bahasa yang diujarkan dari pembicara dan lawan bicara akan menyebabkan timbulnya alih kode. Begitu juga dengan situasi ujaran dari formal ke ujaran tidak formal dapat terjadinya alih kode, topik pembicaraan dapat terjadi alih kode dari yang formal 
ke yang tidak formal disebabkan bahasa pertama yang didapatkan sama. Kontribusi alih kode pada masyarakat amat berarti, dalam hubungannya atas penggunaan ragam bahasa dari seseorang maupun kelompok masyarakat, spesifiknya dalam penggunaan bahasa dari masyarakat yang multingual maupun bilingual [6].

Tahun 2004 adalah bermulanya muncul kata-kata podcast. Ben Hammersley mengatakan podcasting di sebuah artikel miliknya. Munculnya internet menjadikan siaran radio biasa merasa terancam tidak diminati lagi pendengarnya. Mereka melakukan berbagai cara untuk mengelola radio siaran agar mampu beradapatasi terhadap perkembangan teknologi juga minat dari pendengar, terlebih pada cara mengonsumsi konten audio. Strategi yang digunakan adalah dari memvariasi beragam podcast radio. Hal tersebut ternyata cukup terkenal di negara Amerika juga dari negara bagian Eropa, dan juga hal ini mendapatkan untung dalam hal bisnis. Podcast ini menjadikan sebuah peluang untuk mereka pengembang audio, hal tersebut termasuk kepada pengelola siaran radio konvensional di Indonesia. Dalam Fadillah, seperti yang dikatakan oleh Geoghegan dan Klass (2017: 94) kelebihan podcast itu terdapat pada; bisa digunakan dengan cara otomatis, gampang dan kendali berada pada pemakai langsung, praktis (2007). Belakangan ini Podcast juga mengacu pada materi dalam bentuk video. Sehingga pengertian podcast dapat mengacu podcast audio dan video. Istilah podcast diartikan materi audio atau video yang tersedia di internet yang dapat secara otomatis dipindahkan ke komputer ataupun laptop dan diunggah ke media youtube, seperti judul objek skripsi ini yang diambil dari media podcast youtube Deddy Corbuzier[7].

Berlandaskan persoalan bahasa yang terjadi pada penelitian tersebut, tujuan yang hendak didapatkan yaitu berfokus untuk mendeskripsikan jenis alih kode pada podcast Deddy Corbuzier, dan untuk mendeskripsikan faktor penyebab terjadinya alih kode pada podcast Deddy Corbuzier. Juga pembahasan ini bisa dijadikan manfaat teoritis untuk dasar dari teori maupun acuan agar memperkuat gejala perihal aturan sosiolinguistik, spesifiknya mengenai peralihan kode. Secara praktis, kajian ini berguna untuk masyarakat, seperti menjadi sumber pengetahuan mengenai kajian sosiolinguistik. Dan juga dapat berguna untuk guru supaya tetap menganjurkan siswa agar melestarikan bahasa daerah di dari menggunakannya bahasa Indonesia, kajian ini pun diharapkan dapat dijadikan acuan sebagai kajian yang relevan.

\section{METODOLOGI PENELITIAN}

Penelitian ini menggunakan pendekatan kualitatif. Pendapat dari Bogdan dan Taylor (dalam Moleong, 2017: 4) metodologi kualitatif adalah metode pengkajian yang menciptakan data gambaran berbentuk kata-kata tercatat maupun tuturan oleh orang-orang dan karakter yang dapat simak. Bagi mereka, pendekatan ini ditujukan untuk latar dan perseorangan itu secara lengkap. Jadi mengenai hal tersebut tidak boleh memisahkan perorangan maupun organisasi pada faktor maupun asumsi, melainkan butuh mengacunya untuk bagian dari suatu kelengkapan. Lofland dan Loflan mengatakan (dalam Moleong, 2017: 157) sumber data primer pada suatu kajian kualitatif yaitu kata-kata, dan tindakan, dan yang lainnya ialah data tambahan sebagai dokumen dan lainnya. Sumber data pada kajian ini berasal dari sebuah percakapan Deddy Corbuzier dengan bintang tamunya, meliputi, Azka Corbuzier, Nadiem Makarim,Indro Warkop, Sara Fajira, Denny Caknan dan Fiki Naki yang mengandung alih kode di dalam podcast "Deddy Corbuzier". Wujud data pada kajian ini ialah analisis alih kode yang terdapat pada podcast "Deddy Corbuzier". Yang di salin dalam bentuk teks tertulis di dalam podcast ini [8].

Mengamati topik kajian dilaksanakan melalui penyadapan. Dengan kata lain, metode simak secara praktik dilakukan dengan menyadap. agar memperoleh data, pengkaji menyadap pemakaian bahasa, menyadap percakapan seseorang maupun sebagian orang, atau menyadap pemakaian bahasa tulis. Penelitian tersebut memakai metode simak bebas cakap, agar melakukan proses simak maupun cara menyadap, pengkaji sekedar menjadi pengamat maupun penyimak, pengkaji tidak terlibat bicara langsung kepada percakapannya, metode ini sangat cocok diaplikasikan jika data kajiannya merupakan data dokumen atau tulisan [9]. Analisis data yang 
dipakai pada kajian ini, merupakan teknik agih dan padan, metode padan ialah teknik Itu luar, cekung, atau tetap oleh bahasa dan terkait dengan teknik pencocokan dan pencocokan di luar bahasa. Teknik pencocokan di luar bahasa digunakan untuk mempelajari unsur-unsur nonlinguistik seperti: B. Hubungan antara masalah bahasa dan nonbahasa (eksternal) dari segi makna, acuan, konteks tutur, dsb. Teknik distribusi adalah metode analisis data dengan menggunakan determinan yang merupakan poin daripada analisi tersebut. Teknik ini, teknik diaplikasikan dalam kajian tersebut, ialah penyisipan, teknik penyisipan dilakukan menggunakan menyelipkan elemen pada elemen lidah yang ada, dalam hal ini unit lidah yang bersangkutan ditambahkan ke elemen baru dengan tambahan elemen untuk.. Lalu penyampaian hasil analisis yang dipakai pada kajian ini merupakan metode informal. Metode informal islsh kata-kata biasa untuk mengartikan ajaran yang sesuai pada ranahnya, konstrain, dan hubungan antar kaidah [10].

\section{HASIL DAN PEMBAHASAN}

\section{Hasil Penelitian}

Berdasarkan kajian dan analisis data tentang alih kode dalam podcast "Deddy Corbuzier" adalah terdapat banyaknya variasi bahasa yang digunakan dalam video podcast dan terdapat banyak pula faktor penyebab terjadinya peralihan kode dalam pembicaraan podcast tersebut, selain itu juga terdapat informasi yang bermanfaat juga untuk dipelajari oleh siswa.

Tabel 1. Jenis Alih Kode Intern dan Ekstern

\begin{tabular}{|c|c|c|c|c|}
\hline No & Jer & lih Kode & Faktor Penyebab Alih Kode & Frekuensi \\
\hline \multirow[b]{2}{*}{1} & \multirow[b]{2}{*}{ Intern } & $\begin{array}{l}\text { a.Bahasa } \\
\text { Indonesia-Bahasa } \\
\text { Betawi }\end{array}$ & $\begin{array}{l}\text { - keinginan untuk membangkitkan } \\
\text { rasa humor }\end{array}$ & 1 \\
\hline & & $\begin{array}{l}\text { b.Bahasa } \\
\text { Indonesia-Bahasa } \\
\text { Jawa }\end{array}$ & $\begin{array}{l}\text { - keinginan untuk membangkitkan } \\
\text { rasa humor } \\
\text { - lawan tutur atau mitra tutur } \\
\text { - perubahan topik pembicaraan } \\
\text { - penutur atau pembicara }\end{array}$ & $\begin{array}{l}1 \\
2 \\
1 \\
3\end{array}$ \\
\hline \multirow{4}{*}{2} & \multirow{3}{*}{ Ekstern } & $\begin{array}{l}\text { a.Bahasa } \\
\text { Indonesia-Bahasa } \\
\text { Rusia }\end{array}$ & - penutur atau pembicara & 1 \\
\hline & & $\begin{array}{l}\text { b.Bahasa } \\
\text { Indonesia-Bahasa } \\
\text { Rumania }\end{array}$ & - penutur atau pembicara & 1 \\
\hline & & $\begin{array}{l}\text { c.Bahasa } \\
\text { Indonesia-Bahasa } \\
\text { Inggris }\end{array}$ & $\begin{array}{l}\text { - perubahan topik pembicaraan } \\
\text { - penutur atau pembicara } \\
\text { - keinginan untuk membangkitkan } \\
\text { rasa humor } \\
\text { - mitra tutur atau lawan bicara }\end{array}$ & $\begin{array}{l}4 \\
7 \\
1 \\
3\end{array}$ \\
\hline & \multicolumn{3}{|c|}{ Jumlah } & 25 \\
\hline
\end{tabular}

\section{Pembahasan}

\section{Alih Kode Intern dan Faktor Penyebab Alih Kode Intern}

Peralihan kode intern ini ada pada podcast "Deddy Corbuzier" berupa peralihan kode antara bahasa Indonesia beralih pada bahasa Jawa dan peralihan kode antara bahasa Indonesia ke dalam bahasa Betawi, ditemukan sebanyak 8 data. Dan faktor penyebab terbentuknya alih kode intern 
meliputi: keinginan untuk membangkitkan rasa humor, lawan tutur atau mitra tutur, perubahan topik pembicaraan, dan penutur atau pembicara. Salah satu contohnya adalah:

Data berikut ini menunjukan peristiwa alih kode yang membahas tentang pengalaman hidup bintang tamu. Dalam episode yang dibintangi oleh Denny Caknan. Faktor penyebab terjadinya alih kode dari bahasa Indonesia ke bahasa Jawa adalah "keinginan untuk membangkitkan rasa humor". Karena pada awal perbincangan Deddy berkata dengan nada bergurau 'penyanyi kok gak ada kerjaan?' lalu perbincangan beralih kode ke bahasa Jawa dan Denny bertanya 'oh ini mau jadi podcast Jawa juga' dan dijawab oleh Deddy dengan nada bergurau akan menyaingi podcast bahasa Jawanya Denny Caknan. Dan berikut kutipan percakapannya:

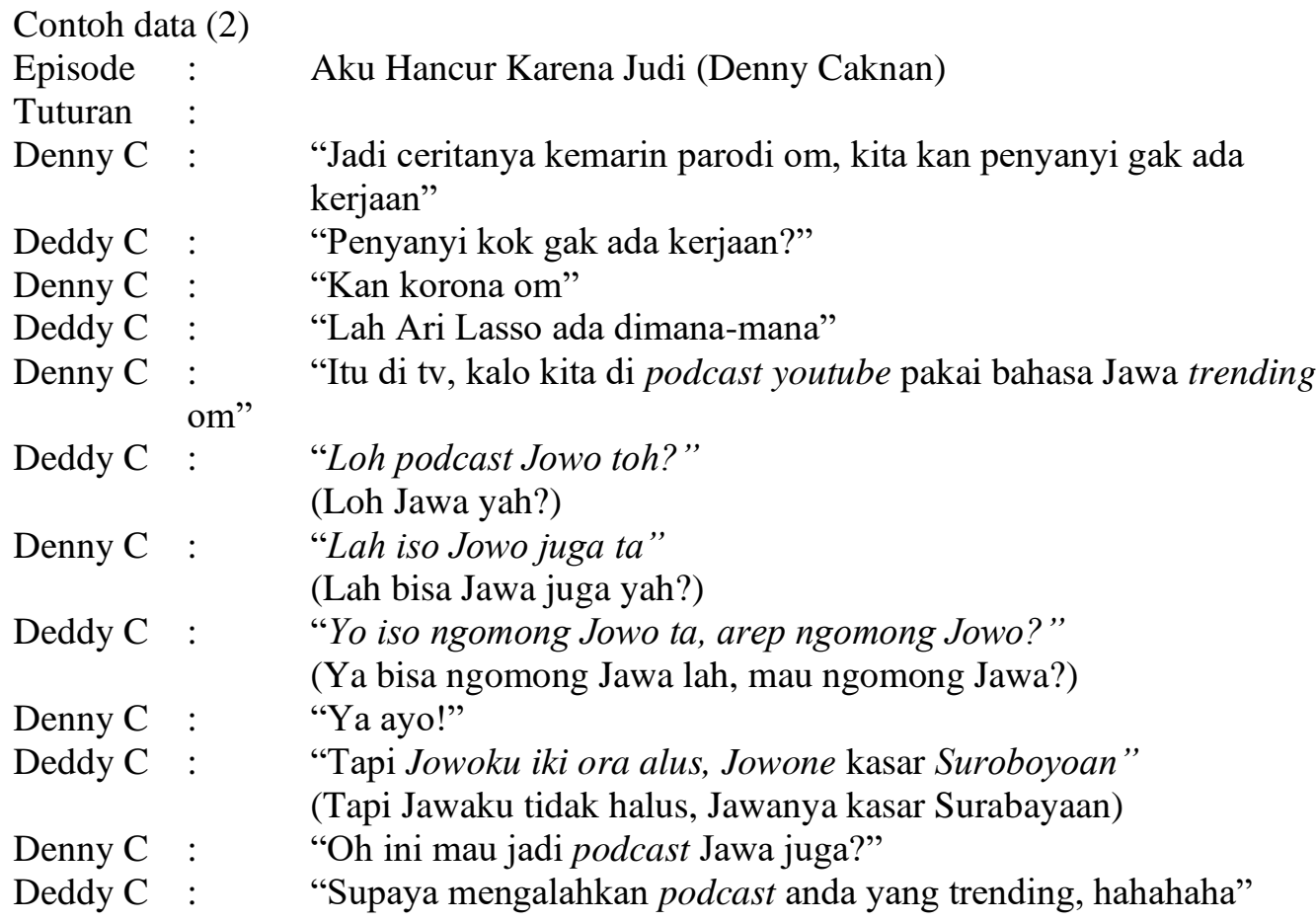

Konteks pada episode kali ini Deddy Corbuzier mengundang bintang tamunya yang merupakan seorang penyanyi pendatang baru yang bernama Denny Caknan, Denny merupakan seorang penyanyi yang sedang naik daun karena lagunya yang berjudul 'Kartonyono Medot Janji', penyanyi kelahiran Pati ini membawakan lagu bergenre pop koplo yang saat ini sedang gemar digandrungi oleh pemuda milenial, dan di dalam video tersebut Denny bercerita tentang perjalanan karirnya sebagai penyanyi, telah melawati banyak ujian hidup, mulai dari terjatuh pada kasus judi hingga meerambah ke judi online yang membuat keluarganya bangkrut, kemudian peristiwa peralihan kode terjadi dalam video ini, Denny menggunakan bahasa Jawa dalam percakapannya karena lawan bicaranya Deddy Corbuzier pun bisa menggunakan bahasa Jawa. Analisis pada data (2), awalnya membahas tentang proyeknya membuat podcast Jawa yang trending di youtube, dan kemudian peralihan kode terjadi ketika dibalas dengan bahasa Jawa oleh Deddy Corbuzier dengan nada candaan bahwa podcast miliknya disaingi oleh Denny Caknan, dengan ditandai kalimat 'lah iso jowo juga ta?' yang artinya 'lah bisa bahasa jawa juga ya?' dan faktor terjadinya alih kode pada percakapan tersebut adalah untuk membangkitkan rasa humor.

\section{Alih Kode Ekstern dan Faktor Penyebab Alih Kode Eksern}

Peralihan kode ini ada pada acara podcast "Deddy Corbuzier" ialah pealihan kode dari bahasa asal yaitu bahasa Indonesia ke dalam bahasa asing. Bahasa luar itu meliputi: bahasa Inggris juga bahasa Rusia ditemukan ada 17 data. Dan faktor terjadinya alih kode ekstern meliputi: 
perubahan topik pembicaraan, penutur atau pembicara, keinginan untuk membangkitkan rasa humor dan mitra tutur atau lawan bicara. Salah satu contohnya adalah:

Data pada episode kali ini di bintangi oleh Azka Corbuzier. Dan dalam perbincangannya membahas tentang kedekatan mereka berdua, juga kehidupan sehari-hari Azka Corbuzier. Faktor penyebab timbulnya peralihan kode yang mulanya bahasa Indonesia ke dalam bahasa Inggris maupun sebaliknya ialah "perubahan topik pembicaraan". Disebabkan karena peralihan kode yang terjadi dalam percakapan tersebut, mulanya mereka membahas tentang sekolah daring, kemudian beralih topik membahas tentang diskon biaya sekolah. Dan berikut kutipan percakapannhya:

Contoh data (14)

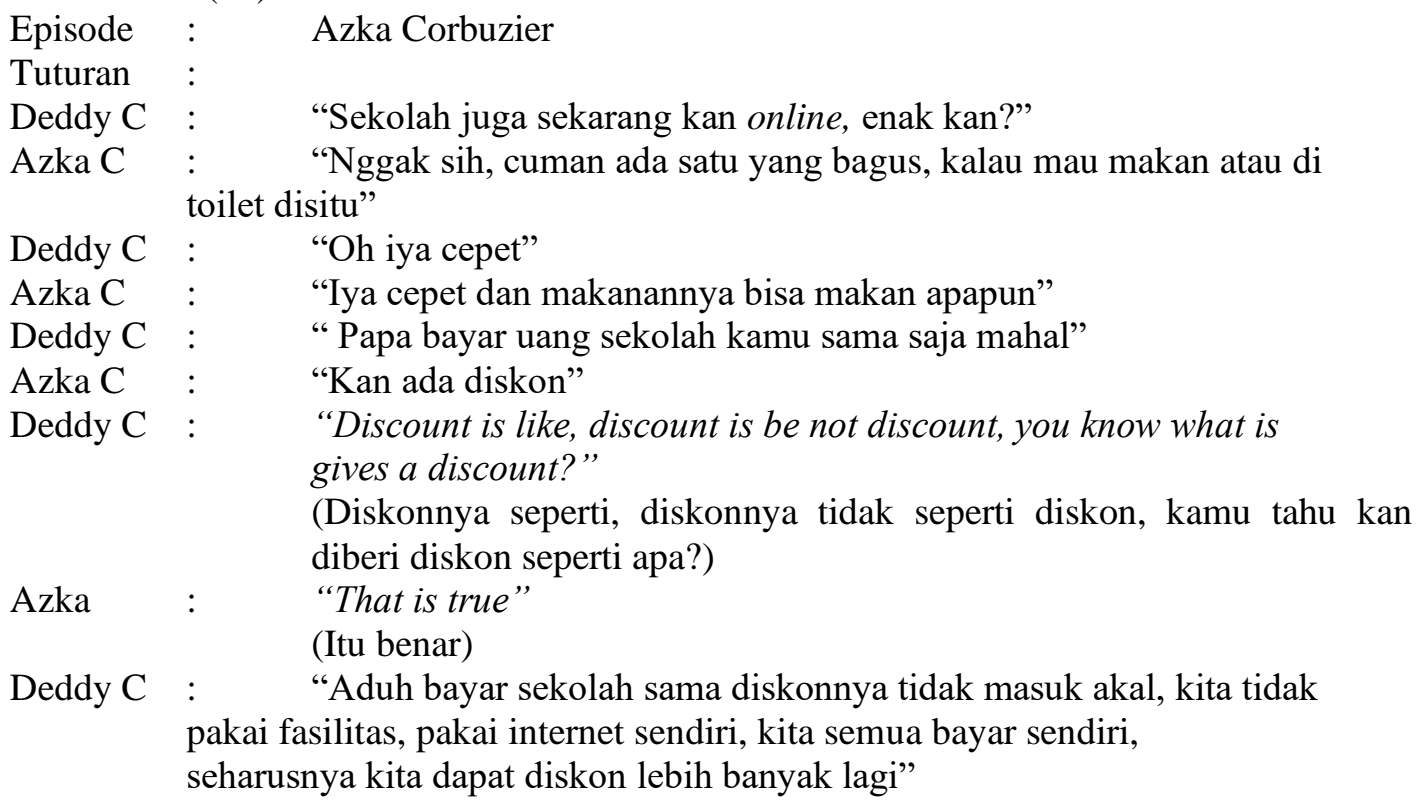

Konteks pada episode kali ini Deddy Corbuzier mengundang bintang tamunya yang merupakan anak kandungnya sendiri yang bernama Azka Corbuzier, di dalam video tersebut Deddy dan Azka berbincang mengenai pendidikannya selama pandemi ini dan biaya yang tetap sama meskipun dalam masa seperti ini, juga kegiatan yang Azka lakukan dirumah semasa pandemi ini, peralihan kode dalam video ini ketika percakapan beralih ke bahasa Inggris sebagai bahasa keduanya, Azka yang terbiasa menggunakan bahasa Inggris karena di sekolahnya yang merupakan sekolah internasional yang mewajibkan murid-muridnya menggunakan bahasa inggris dalam percakapan formal maupun informal.

Analisis pada data (14) ini pada mulanya Deddy Corbuzier menggunakan bahasa Indonesia dan membahas tentang sekolah daring, kemudian alih kode terjadi ketika Deddy Corbuzier menggunakan bahasa Inggris saat topik pembicaraan berubah, yang mulanya membahas sekolah daring kemudian membahas tentang biaya sekolahnya, dengan ditandai kalimat 'Discount is like, discount is be not discount, you know what is gives a discount?' yang artinya 'Diskon itu seperti, diskon bukan seperti ini, kamu tahu sebuah pemberian diskon itu seperti apa?'. Kemudian faktor penyebab alih kode tersebut terjadi di dalam percakapan adalah perubahan topik pembicaraan, ketika pembicaraan pertama membahas tentang enaknya pembelajaran online kemudian berganti tentang diskon biaya sekolah.

\section{SIMPULAN}

Dari kajian juga analisis ini tentang peralihan kode pada podcast "Deddy Corbuzier" adalah terdapat banyaknya variasi bahasa yang digunakan dalam video podcast dan terdapat banyak pula faktir penyebab terjadinya peralihan kode dalam pembicaraan podcast tersebut, selain itu juga 
terdapat informasi yang bermanfaat juga untuk dipelajari oleh siswa. Maka simpulan pada kajian ini diperoleh ialah sebagai berikut.

Jenis peralihan kode pada podcast "Deddy Corbuzier" terdapat dua jenis alih kode, meliputi alih kode intern, dan alih kode ekstern. a) alih kode intern meliputi: peralihan kode dari bahasa Indonesia ke bahasa bahasa Betawi dan peralihan kode dari bahasa Indonesia ke dalam bahasa Jawa. b) kemudian peralihan kode keluar atau ekstern ialah: peralihan kode bahasa Indonesia ke bahasa Rusia, peralihan kode bahasa Indonesia ke bahasa Rumania, dan peralihan kode bahasa Indonesia ke dalam bahasa Inggris.

Faktor-faktor penyebab terjadinya peralihan kode ke dalam atau intern meliputi: a) keinginan untuk membangkitkan rasa humor, b) Lawan tutur atau mitra tutur, c) Perubahan topik pembicaraan, d) penutur atau pembicara. Kemudian data yang diperoleh dalam percakapan video podcast tersebut terdapat alih kode ekstern meliputi: a) penutur atau pembicara, b) Perubahan topik pembicaraan, c) keinginan untuk membangkitkan rasa humor, d) mitra tutur atau lawan bicara

\section{REFERENCES}

[1] Amaliani,Shofi, Leli Triana, dan Agus Riyanto, "Alih Kode dan Campur Kode pada Proses Belajar Di TK Pertiwi Longkeyang dan Implikasinya", Jurnal Skripta., vol 6, no 2, 2020, [Online]. Available: https://journal.upy.ac.id/index.php/skripta/article/view/900

[2] Thesa, Khodiyo, "Penggunaan Alih Kode dalam percakapan pada jaringan whatsapp oleh mahasiswa knb yang berkuliah di Universitas Sebelas Maret", Journal of Linguistic, vol 2, no 1, 2017, [Online]. Available: https://jurnal.uns.ac.id/pj1/article/download/1720/10076

[3] Munandar, Aris. "Alih Kode dan Campur Kode dalam Interaksi Masyarakat Terminal Mallengkeri Kota Makasar. Jurnal Eprint, 2018, [Online]. Available: https://jurnal.uns.ac.id/pjl/article/download/1720/10076

[4] Kholifah Umi dan Haryadi, "Wujud Pilihan Kode Tutur Mahasiswa Aceh pada Ranah Pergaulan di Semarang", Jurnal Seloka. vol 6, no 2, 2017, [Online]. Available: https://journal.unnes.ac.id

[5] Indriyani, Yekti, "Alih Kode dan Campur Kode Antara Penjual dan Pembeli Di Pasar Prembun Kabupaten Kebumen (Sebuah Kajian Sosiolinguistik)", Jurnal Bahtera, vol 6, no 12, 2019, [Online]. Available: http://ejournal.umpwr.ac.id/index.php/bahtera/article/view/6032

[6] Henaulu, Maryam dkk, "Alih Kode dan Campur Kode Penjual dan Pembeli Di Pasar Tradisional Namlea", Jurnal LOA: Jurnal Ketatabahasaan dan Kesusatraan, vol 15, no 1, 2020, [Online]. Available: https://ojs.badanbahasa.kemdikbud.go.id/jurnal/index.php/loa/article/view/2170

[7] Fadilah, Efi, Pandan Yudhapramesti, Nindi Arist, "Podcast Sebagai Alternatif Distribusi Konten Audi", Jurnal Kajian Jurnalisme, vol 1, no 1, 2017, [Online]. Available: https://jurnal.unpad.ac.id/kajian-jurnalisme/article/view/10562

[8] Meleong, Lexy J., "Metodologi penelitian kualitatif", 2017, PT Remaja Rosdakarya Offset, Bandung.

[9] Muhammad, "Metode Penelitian Bahasa", 2011, Ar-Ruzz Media, Jogjakarta.

[10] Haryati, Alih Kode dan Campur Kode percakapan dalam film Ketika Cinta Bertasbih dan Implikasinya terhadap Pembelajaran Bahasa Indonesia di SMA, Universitas Pancasakti Tegal, 2018, Tegal. 